\title{
Polfri nevosisa
} ARTIGOS - Temas Livres

\section{A CIDADE E A QUESTÃO DA TERRA E DA MORADIA: O caSO de Pelotas-RS}

\author{
Cristine Jaques Ribeiro ${ }^{1}$ \\ Nino Rafael Medeiros Kruger ${ }^{2}$
}

\section{Resumo}

$\mathrm{O}$ artigo visa problematizar o tema da cidade, apresentando a questão da terra e da moradia como ativos financeiros resultantes da especulação imobiliária no Brasil. Analisa o espaço relacionado ao tema do direito à cidade, bem como discute a questão da financeirização expondo a falta de uma política urbana capaz de garantir a proteção no campo dos direitos sociais. Para evidenciar a lógica financista, apresenta a implantação do Programa Minha Casa Minha Vida e o contraponto das ocupações urbanas no município de Pelotas no Estado do Rio Grande do Sul. Utiliza pesquisa bibliográfica, pesquisa documental e estudo de campo. Conclui que os processos de desigualdades socioambientais são resultantes da defesa da propriedade privada e que a mudança só ocorrerá por intermédio da luta pela reforma urbana e agrária, reafirmando políticas sociais que garantam a moradia como direito universal.

Palavras-chave: Programa Minha Casa Minha Vida, cidade, propriedade privada, financeirização ocupações urbanas.

\footnotetext{
Assistente Social, Doutora em Serviço Social pela Pontifícia Universidade Católica do rio Grande do Sul (PUCRS), Docente do Curso de Graduação em Serviço Social e Pós-graduação em Política Social e Direitos Humanos Universidade Católica de Pelotas (UCPel), Coordenação do GEP Questão agrária, urbana e ambiental Observatório dos Conflitos da Cidade. E-mail: cristinejrib@gmail.com / Endereço: Universidade Católica de Pelotas - UCPel: Campus 1, Rua Gonçalves Chaves, 373, Pelotas, RS. CEP: $96015-$ 560 .

2 Assistente Social, Doutorando em Políticas Sociais e Direitos Humanos pela UCPel, Bolsista CAPES. E-mail: contatorafaelkruger@gmail.com
} 
THE CITY AND THE ISSUE OF LAND AND HOUSING: the case of Pelotas-RS

\begin{abstract}
The article aims to problematize the theme of the city by presenting the question of land and housing as financial assets resulting from real estate speculation in Brazil. It analyzes the space relating to the theme of the right to the city as well as discusses the issue of financialization exposing the lack of an urban policy capable of guaranteeing protection in the field of social rights. In order to demonstrate the financial logic, the implementation of the My House My Life Program and the counterpoint of urban occupations in the municipality of Pelotas in the State of Rio Grande do Sul are presented. It carried out bibliographical research, documentary research and field study. It concludes that the processes of socio-environmental inequalities result from the defense of private property and that change will only occur through the struggle for urban and agrarian reform, reaffirming social policies that guarantee housing as a universal right.
\end{abstract}

Key words: My Home My Life Program, city, private property, financialization, urban occupations.

\title{
1 INTRODUÇÃO
}

A cidade é tema cuja exigência é que ultrapassemos as fronteiras do conhecimento, pois não cabe em uma única definição a sua existência. Para alguns, a cidade será espaço de convivência, de troca de afetos, de perpetuação de histórias, de vínculos, de saberes, de reprodução da vida. Para outros, a cidade será produto de interesse mercantil passível de ser comercializado, cujo foco é a produção e o consumo, oportunizando apenas aqueles que conseguem participar desse processo.

Nessa dinâmica, a cidade se apresenta composta por diversos agentes que buscam no cenário da vida cotidiana existir e criar dispositivos capazes de viabilizar resistências coletivas. Alguns agentes utilizam ferramentas no território para participar na sociedade de forma a denunciar os processos de desigualdade. As ocupações de terra no solo urbano são as ferramentas que sofrem ataques constantes por parte das construtoras e do Estado. São comuns as recorrentes remoções, desapropriações ou tentativas de regularizações utilizadas para desmobilizar ações coletivas, bem como fragilizar as condições de habitar o solo urbano para inúmeras famílias de trabalhadores desempregados ou assalariados. 
As experiências das famílias com o Programa Minha Casa Minha Vida viabilizam a problematização da política urbana no país que ressoa em todo território nacional. Esse programa que subsidia a população para adquirir a casa própria o faz sem nenhum compromisso com o direito universal da moradia com qualidade, pois constrói a imagem de propriedade para diversas famílias não revelando o que de fato está na base de interesse do governo e das construtoras sobre esse subsídio.

Para o mercado imobiliário no Brasil, as medidas de caráter regulatório vão constituir antecedentes que consolidarão a implantação do Programa Minha Casa Minha Vida. Essa consolidação fortaleceu a segregação imposta para legitimar os territórios separados na mesma cidade. Cada grupo social, seja população empobrecida ou classe média, por exemplo, terá o domínio da vida privada com seu grupo familiar. Sob o discurso de defesa da intimidade. a micropolítica vai revelar o que a macro política impõe. O controle da vida por parte do Estado aliado às construtoras será a tônica das operações. No entanto, para ultrapassar o conceito de propriedade privada tão amplamente defendido pelas forças econômicas no País, a questão do direito à posse denuncia o discurso da irregularidade e da ilegalidade de tal questão. A função social da terra evidenciada no Estatuto da cidade e que deve ser bem resguardada em cada plano diretor nos municípios brasileiros, coloca em questão se a população está com sua qualidade de vida garantida. Então, este estudo pretende apresentar o antagonismo do discurso de regularização como garantia do direito à moradia que, ao contrário, vem inviabilizando a permanência das populações em seus espaços de habitação.

Sendo assim, este trabalho objetiva problematizar o tema da cidade e sua íntima relação com os processos de financeirização da terra e da moradia, consequentemente da política urbana, fazendo um recorte - a partir do estudo de campo, documental e bibliográfico -, da realidade do município de Pelotas, localizado no Estado do Rio Grande do Sul. Para tanto, a ocupação e uso do solo serão questões a ser refletidas no sentido de reconhecer com essa experiência apresentada o quão longe está a efetivação de uma política urbana construída a partir da realidade em que vivem as populações em situação de pobreza. 


\section{O ESPAÇO NO DIREITO À CIDADE}

Para que seja pensado o tema do direito à cidade, torna-se necessário relacioná-lo com a construção do período urbano no cenário histórico. Lefebvre (1999) afirma que existiram três períodos: o agrário, industrial e o urbano. Todos eles com representações importantes no que se refere a sua constituição. $\mathrm{O}$ período urbano surge das condições político-históricas determinadas pelo período industrial fruto de um contexto de não desenvolvimento. A era urbana revela problemas mundiais que necessitam reconsiderar todos os símbolos, todas as noções e todos os conceitos de ciência. No entanto, nesse processo de mudanças de períodos, as populações reproduzem ideias e práticas do período anterior que de certa forma revelam pensamentos ultrapassados frente às mudanças muito rápidas dos modos de vida da sociedade. Consequentemente, a noção de espaço urbano demora a acontecer, alimentando as segregações aceleradas.

Os urbanos transportam o urbano consigo, ainda que não carreguem a urbanidade! Por eles colonizado, o campo perde as qualidades, propriedades e encantos da vida camponesa. O urbano assola o campo; este campo urbanizado se opõe a uma ruralidade sem posses, caso extremo da grande miséria do habitante, do habitat, do habitar. (LEFEBVRE, 2016, p. 117).

É importante afirmar que a reforma agrária na primeira metade do século XX foi a proposta forte que desencadeou lutas como a revolução Russa e Chinesa, muito embora os países africanos, asiáticos e latino-americanos ainda estejam longe disso. A reforma não se caracteriza como revolução, mas conseguiu provocar ideias sobre a necessidade de ocupação de terra para forçar a distribuição equitativa para as populações trabalhadoras no Mundo. Consequentemente, pensar a questão urbana sob a perspectiva do solo construído é tão crucial quanto a defesa do solo cultivável, uma questão agrária. Contudo, pensar a questão do solo construído não garante a qualidade de vida das populações, pois a reforma urbana tem suas limitações operacionais e institucionais, porém, deflagra as condições que vivem diferentes segmentos e denuncia tais condições. Um exemplo é a possibilidade de identificar o crescimento acelerado da especulação imobiliária evidenciando que o solo construído é solo da propriedade privada.

No que se refere aos modos de viver das populações que habitam as periferias, os subúrbios, as vilas, como desejarmos classificar, 
revela-se que não há uma síntese entre rural e urbano para a consolidação do espaço-período-urbano. A estratificação foi construída para separar pobres e ricos na cidade particularizando lugares de convivência para grupos diferenciados com a intenção de colocar trabalhadores operários em determinadas funções com objetivo de manter a base de sustentação do capital.

Os espaços na cidade urbana se tornam especializados, cujo objetivo é comercializar, torná-los rentáveis, como é o caso dos esportes, mercados, escritórios e praças, isolando-os para serem vendidos no conjunto da sociedade. Como lembra Lefebvre (1999), os espaços especializados são espaços mortos porque só correspondem a uma atividade em dado momento. São espaços privativos, privatizados, perdem o sentido e o uso comum, que é o sentido de compartilhamento dos citadinos. Os espaços especializados fragmentam-se e se isolam inviabilizando qualquer manifestação cívica.

Surge, então, um urbanismo que pretende organizar a cidade, uma ideia de ciência do espaço, porém se impõe, sobretudo, nas medidas administrativas entre decisões do poder estatal e os interesses privados. Essa forma de organizar a cidade limitou-se a um tipo de tecnocracia preocupada com um tipo de planificação que não responde aos desejos e necessidades da população. Sendo assim, a tecnocracia urbanística se submete aos ditames dos financistas que decidem a vida da cidade. Com a tecnocracia o habitar ficou submetido ao habitat. O espaço criado pelos coletivos é desconsiderado para que as projeções impostas se tornem realidade no cotidiano urbano. O funcionamento, o movimento, a territorialização da vida social é comercializada numa relação de dependência frente ao colonizador.

O urbanismo dos administradores ligados ao setor público (estatal). Este urbanismo se pretende científico. Baseia-se ora numa ciência, ora em pesquisa que se pretendem sintéticas [...]. Este cientificismo, que acompanha as formas deliberadas do racionalismo operatório, tende a negligenciar o "fator humano", como se diz [...] Extrapola-se a partir de uma ciência, de uma análise fragmentária da realidade considerada [...]. Esse urbanismo tecnocrático e sistematizado, com seus mitos e sua ideologia [...] não hesitaria em arrasar o que resta da Cidade para dar lugar aos carros, às comunicações [...] (LEFEBVRE, 2016, p. 31).

A ocupação do espaço construído impõe aos coletivos um tipo de apropriação conforme aos interesses econômicos hegemônicos. A lógica financista dispõe de compartimentos funcionais que exigem 
comportamentos funcionais decidindo onde as populações podem se alimentar, se deslocar, trabalhar, fazer compras, divertir-se. "O espaço se torna mais articulado às relações funcionais, e mais desarticulado quanto ao comando local das ações que nele exercem." (SANTOS, 2009, p. 49).

Então, a diferença entre espaço de uso e espaço de troca se sobressai, pois o primeiro aposta no modo como a população transforma a apropriação da terra, a partir de seus desejos, das escolhas, da organização do dia a dia; o segundo investe na possibilidade de comercializar a terra tornando-a produto e, portanto, passível de troca, objeto de consumo. Como lembra Lefebvre (1999), a linguagem de um espaço apropriado é completamente diferente do espaço comercializado.

O Estado, como agente direto das práticas no espaço, formatou as linguagens na perspectiva de neutralizar a participação e a resistência dos grupos, no entanto, é importante reinventar o espaço. Essa perspectiva sugere que a criação do espaço aconteça a partir dos processos autogestionários remando contra a função instituída pelos projetos urbanísticos. "A vida urbana pressupõe encontros, confrontos das diferenças, conhecimentos e reconhecimentos recíprocos [...] dos modos de viver dos padrões que coexistem na cidade." (LEFEBVRE, 2016, p. 22).

Pensar no direito à cidade é problematizar de que cidade está se falando, a quem ela pertence e o que ela é para seus citadinos. $\mathrm{Na}$ realidade cotidiana o que se encontra são mecanismos de negação do direito das populações que vivem em situação de posse, de empobrecimento de segregação social. Quando nos perguntamos de quem é a cidade, somos convidados a perceber que o espaço da cidade está dividido, onde existem aqueles que podem consumir e os que não podem. Consequentemente, os sentidos produzidos por esses grupos divididos são sentidos opostos e que apresentam uma cidade mercadolmercadoria.

Quando a cidade se apresenta como propriedade privada, ela se torna capturada pelas normas do trabalho explorado. São aqueles que detêm os meios de produção que vão regular a lógica do trabalho assalariado, subempregado ou desempregado na cidade. Então, a cidade é produto da sociedade, sua invenção social. Se a sociedade criou a cidade, ela criou as regras de participação, de segregação, de exploração, bem como de lutas e de denúncias coletivas. Engels 
(1987, p. 191), quando se refere ao Estado, nos convida a relacioná-lo com a cidade:

O Estado não é pois, de modo algum, um poder que se impôs à sociedade de fora para dentro; tampouco é " a realidade da idéia moral", nem a "imagem e a realidade da razão", como afirma Hegel. É antes um produto da sociedade, quando esta chega a um determinado grau de desenvolvimento; é a confissão de que essa sociedade se enredou numa irremediável contradição com ela própria e está dividida por antagonismos irreconciliáveis que não consegue conjurar.

No entanto, as populações organizadas reverberam os sentidos da cidade. Os coletivos anunciam em suas lutas o desejo de construir outra cidade. Uma construção para a maioria. Esses coletivos fortalecidos em seus movimentos sociais anunciam por qual cidade estão lutando e querem conquistar. Desejam-na com casas e áreas verdes distribuídas, nas quais todos possam compartilhar sua vida de modo coletivo e equitativo, e isso poderá acontecer na potencialização das denúncias para forçar mudanças estruturais no conjunto da cidade. A cidade tem que se tornar de uso coletivo, público, para todos.

\section{A FINANCEIRIZAÇÃO DA TERRA E SUAS CONSEQUÊNCIAS NA CIDADE}

Para iniciar a reflexão sobre o tema da financeirização, antes se torna importante reafirmar o pensamento sobre a cidade do ponto de vista da desconstrução da fronteira imposta entre o rural e o urbano. Pensar a cidade exige refletir sobre o discurso que impõe a defesa do direito à propriedade desconsiderando a legitimidade do direito à posse. (ALFONSIN, 2006). Para tanto, é bom sublinhar a relevância para discussão do que vem a ser a função social da terra $\mathrm{e}$, consequentemente, a função social da cidade que nos conduz para a análise da desigualdade socioambiental, na qual vivem as comunidades periféricas.

Com essas primeiras considerações, a presente pesquisa parte para a perspectiva crítica de que a terra é mercadoria, portanto a cidade e, consequentemente, a moradia, também o são. A estrutura fundiária se apresenta através da concentração e distribuição de terras, pois o espaço agrário no Brasil se divide por diferentes faixas de tamanhos que são as pequenas, médias, grandes e enormes extensões de terras. 
As pequenas extensões de terra existem em maior quantidade, mas em menor espaço, no entanto, são elas que produzem os alimentos que abastecem o mercado interno. As médias extensões abastecem a indústria e grandes redes varejistas. As grandes extensões de terras são pouco utilizadas, produzindo especialmente a monocultura para exportação, e assim, como as enormes extensões de terra, estão nas mãos de poucos, mas ocupam o maior espaço da estrutura fundiária, revelando o predomínio do latifúndio. Assim foi se constituindo a cidade como espaço desigual.

Com essas simples considerações, percebe-se que a propriedade privada se sobressai. O solo urbano sofre a mesma influência com a perspectiva da financeirização que é alimentada pela crise financeira mundial, gerando a crise da moradia. Direitos que devem ser viabilizados pelo Estado na proteção e na garantia da qualidade de vida da população trabalhadora são negados, pois a perspectiva é de fortalecer a intervenção globalizada do capital integrado.

\begin{abstract}
As reformas urbanas, realizadas em diversas cidades brasileiras entre o final do século XIX e início do século XX, lançaram as bases de um urbanismo moderno "à moda" da periferia. Realizavam-se obras de saneamento básico para eliminação das epidemias, ao mesmo tempo em que se promovia o embelezamento paisagístico e eram implantadas as bases legais para um mercado imobiliário de corte capitalista. A população excluída desse processo era expulsa para os morros e franjas da cidade. (MARICATO, 2013, p. 17).
\end{abstract}

Com esse quadro podemos problematizar a questão da colonização da terra e da moradia com várias versões: a primeira versão é a defesa da propriedade privada via crédito hipotecário. Modelo ligado ao mercado global financeiro, realidade que aconteceu muito fortemente nos EUA, onde a população empobrecida passou a viver nos carros porque perdeu sua casa. A outra versão diz respeito ao subsídio à demanda, que é o caso do Programa Minha Casa, Minha Vida. O Estado repassa dinheiro para comprar o que o mercado oferece, modelo que vende o desejo da compra da casa própria. O Estado dá um subsídio para que a população empobrecida possa comprar a moradia ofertada pelas construtoras privadas. Isso serve como ferramenta de desarticulação das ocupações de terra no espaço urbano. (ROLNIK, 2015).

E a última versão é a do Microfinanciamento. Como tornar a favela um campo de investimento para o capital financeiro? Como tocar nos mais pobres? Como a população empobrecida não tem 
renda que garanta a segurança para pagamento de um empréstimo solicitado, será então cobrado dela os maiores juros. No entanto, a quantidade de recursos públicos viabilizados pelo Estado para isenções fiscais de Empresas é imenso. Porém, essa dinâmica sustenta o discurso de que não existem recursos para subsidiar os mais pobres, forçando a destruição de uma política de moradia que responda às necessidades da população. Na verdade, o que acontece é a mudança de rota dos recursos públicos. (ROLNIK, 2015).

A lógica imposta por essas três versões é um processo global de destruição da habitação como política social e como direito humano. O imaginário do Estado de Bem-Estar como provedor da educação, saúde, direito universal ao trabalho e da moradia, em alguns países é destruída e, no caso brasileiro, nunca realizada. Com a globalização, fortalece-se um capital que não tem pátria, não contribui com impostos, que precisa extrair renda e se remunerar através de juros. No entanto, esse capital está especificamente alimentado na economia política do lugar principalmente pelos Estados. (ROLNIK, 2015). "[...] além dos territórios específicos e separados para cada grupo social, além da separação das funções morar e trabalhar, a segregação é patente na visibilidade da desigualdade de tratamento por parte das administrações locais.” (ROLNIK, 2012, p. 47).

Então, uma questão é pensar como os Estados destruíram as condições existentes de política social através das privatizações em massa. Destruíram através da desestabilização da política de controle dos aluguéis bem como da desmontagem das instituições de proteção à moradia dos mais pobres. (ROLNIK, 2015).

Pessoas que convivem anos, construindo suas histórias de vida, são deslocadas para conjuntos habitacionais e, com isso se retira o direito de existir de milhares de famílias. Constrói-se um produto de baixa qualidade, pois a terra periférica é terra barata, mas sem oportunidade de desenvolvimento humano.

As remoções revelam o tipo de política urbana vinculado ao processo de financeirização apostando na construção de shopping centers, entre outros empreendimentos, que gerem lucro num complexo controlado pelo capital financeiro. Com essa dinâmica instaurada as remoções são feitas, pois a terra não pode ser ocupada por pobres e sim por produtos.

A ocupação do solo obedece a uma estrutura informal de poder: a lei de mercado precede a leilnorma jurídica. Esta é aplicada de 
forma arbitrária. A ilegalidade é tolerada porque é válvula de escape para um mercado fundiário altamente especulativo. Tanto a argumentação de cunho liberal quanto a estatizante são utilizadas para assegurar manutenção de privilégios. Regulação exagerada convive com total laissez faire em diferentes áreas de uma mesma cidade. (MARICATO, 2013, p. 83).

Por isso as populações são retiradas para criar a imagem de cidade sem pobres. E a imagem de uma cidade onde ninguém vai estar fora do lugar, uma visão positiva e funcional da cidade, ou seja, o pobre deve ficar lá na periferia onde não tem cidade e nas áreas mais centrais só os usos mais rentáveis. (ROLNIK, 2015). A construção de um imaginário e um estigma do morador da periferia e dos conjuntos habitacionais se fortalece através do discurso da violência e do perigo, desqualificando famílias inteiras. Discurso que cola nos corpos dos mais pobres a responsabilidade dos problemas na cidade. Esse discurso expressa as profundas desigualdades que sofrem aqueles que habitam a periferia. "É como se a cidade fosse demarcada por cercas, fronteiras imaginárias, que definem o lugar de cada coisa e de cada um dos moradores." (ROLNIK, 2012, p.45).

Então, a arquitetura constituída para as cidades é uma arquitetura imposta, e a política urbana abre espaço para que a fronteira da especulação imobiliária possa se expandir sobre as áreas. As operações dos Megaeventos são um exemplo desse processo.

Portanto, uma remoção é sempre uma violência, porque rompe com o vínculo dos sujeitos com seu território de vida. A relação dos citadinos com seu habitar ultrapassa o que está instituído, pois a perspectiva que se dá em relação ao habitar tem outra dimensão. A casa existe para além da materialidade da paréde e do teto, ela é o vínculo de uma comunidade com o território. É a capacidade que esses atores têm de acessar os direitos humanos e sociais. (ROLNIK, 2015). Com essa perspectiva existe outro tipo de relação com o território para além das necessidades materiais propriamente ditas.

Por fim, a ideia da propriedade privada individual é central para esse modelo, pois permite que o pedaço de terra se transforme num ativo financeiro que só pode ser acessado via mercado. Pressupõe um só tipo de vínculo das pessoas com o espaço que é a propriedade registrada.

As reformas urbanas, o controle sobre a propriedade e o uso do solo subordinaram a propriedade imobiliária ao circuito financeiro 
nos países do Primeiro Mundo. Essa regulamentação e a extensão da infraestrutura urbana é que garantiram a extensão do direito à moradia e do direito à cidade. No Brasil e nos demais países da América Latina o patrimonialismo continua a marcar as relações de poder político e continua resistindo à reforma agrária e urbana. (MARICATO, 2013, p. 84).

As políticas fundiárias vão fragilizando todo tipo de vínculo frente a todas as formas de ocupação para a garantia da propriedade privada que se torna hegemônica e dominante, com a intenção de fortalecer todas as formas de remoções, sem garantia de direitos, sob o discurso da transitoriedade e assim o não reconhecimento deste território na cidade. (ROLNIK, 2015).

\section{PROGRAMA MINHA CASA MINHA VIDA - PMCMV - E AS OCUPAÇÕES URBANAS NO MUNICÍPIO DE PELOTAS}

Diante dos processos anteriormente expostos, passa-se a refletir sobre a produção habitacional do PMCMV e o aumento das ocupações irregulares de terra para fins de moradia no município de Pelotas, entendendo que o acesso à cidade engendra um processo desigual no acesso a equipamentos e serviços urbanos. Equipamentos que passarão a ser tratados enquanto bens e consumo na reconfiguração instituída pelas modernas formas de governabilidade pautadas pelo planejamento estratégico. "Transformada em coisa a ser vendida e comprada, tal como a constrói o discurso do planejamento estratégico a cidade não é apenas uma mercadoria mas também, e e sobretudo, uma mercadoria de luxo, destinada a um grupo de elite de potenciais compradores." (VAINER, 2013, p. 83).

Uma vez que se tornou objeto de consumo, deixou de ser direito universal, criando-se a tensão que impõe a determinados grupos sociais procedimentos muitas vezes por eles questionados, como a ocupação de terras, por exemplo. Pois a estrutura desigual de distribuição fundiária reafirma que a cidade esteja ao alcance de uma minoria com possibilidade de ganhar sobre o que nela investe, restando â maioria, gastar nela o que ganha. (ABRAMO, 2007).

A redefinição do conceito de cidade perpassada pela reconfiguração da governabilidade intenta tornar inoperante sua essência de polis, acabando por imprimir uma identidade hibrida de objeto de consumo, empresa e pátria, gerida por um: 
[...] governo forte, personalizado, estável, apolítico, carismático, expressando a vontade unitária de toda uma cidade de manter a trégua e a coesão interna [...] transformando-a em mercadoria, em empresa ou em pátria, definitivamente a estratégia conduz a destruição da cidade como espaço da política, como lugar de construção da cidadania (VAINER, 2013, p. 97 - 98).

Nessa relação escondem-se as raízes dos principais problemas das cidades modernas, fundamento da segregação socioespacial potencializada pelo PMCMV. Concentração fundiária, financeira e política, com base na atuação do poder público como agente financiador do capital, fomentando e aprofundando as desigualdades relativas.

Nesse sentido é que se passa a analisar a produção da habitação em Pelotas a partir de uma reflexão sobre o grupo que deveria ter sido trabalhada enquanto prioritário para o desenvolvimento dos programas habitacionais no município, conforme consolidado pela legislação federal que dispõe sobre o PMCMV (BRASIL, 2009).

No ano de 2013 (ALVES, 2013) fora apresentado o primeiro levantamento do município quanto a suas áreas de ocupações irregulares para moradia, mesmo ano no qual foi apresentado o levantamento do Plano Local de Habitação de Interesse Social (PELOTAS, 2013), normativa federal para o acesso a recursos do PMCMV.

O primeiro estudo aponta que naquele período o número de áreas de ocupações irregulares era de 156 (cento e cinquenta e seis), onde habitavam mais de 60 mil pessoas, em cerca de 11 mil residências. (ALVES, 2013). Áreas estas consideradas irregulares por não contarem com infraestrutura urbana e regularização documental, que correspondia a $80 \%$ do déficit habitacional apresentado pelo PLHIS, de 13.598 (treze mil quinhentos e noventa e oito) moradias. Tal cálculo inclui domicílios improvisados, precários e etc. (PELOTAS, 2013).

Por se tratar de famílias localizadas na faixa de renda considerada prioritária pelo PMCMV (BRASIL, 2009), entende-se que os habitantes destas deveriam ter recebido um tratamento distinto na execução da política, mas a atualização dos dados quanto às ocupações irregulares e a produção do PMCMV dos últimos levantamentos apontam para o fato de que ocorreu um aumento do número de áreas de ocupação, mesmo diante de uma produção habitacional substancial, pois até junho de 2017, 205 (duzentos e cinco) áreas 
de ocupação irregular estavam cadastradas no município (ALVES, 2017).

O estudo atualizado sobre essas áreas aponta para "[...] mais de 90 mil pessoas" habitando em tal situação, "[...] quase $1 / 3$ da população" da cidade (ALVES, 2017, p. 26)

Cabe destacar ainda que, conforme aponta o estudo, por questões políticas a secretaria de habitação fora extinta durante certo período, tendo sido retomados os trabalhos 2 (dois) anos após sua extinção. Ainda que o estudo resgate o orçamento municipal para o ano de 2016, apontando que este foi de 1.250.000.000,00, tendo sido disponibilizado para habitação $\mathrm{R} \$ 140.000,00$, enquanto para a Assessoria de Comunicação R \$ 2.600.000,00, e o legislativo R\$ 18.100.000,00 no mesmo ano (ALVES, 2017), esses números representam as prioridades eleitas pela gestão municipal, que disponibilizou para a habitação e regularização fundiária menos de $6 \%$ do que foi disponibilizado para propaganda, segundo o exemplo.

Soma-se a isso o fato de que a produção habitacional do PMCMV entre os anos de 2009 e 2016 - com ênfase a partir de 2013, quando foram produzidos 41 (quarenta e um) empreendimentos, possibilitou a construção de 60 (sessenta) empreendimentos, que totalizaram a quantia de 11.919 unidades habitacionais. (PINTO, 2016). Quando relativizado ao déficit habitacional do município, torna possível vislumbrar que tal produção poderia ter solucionado o problema habitacional local, pois o déficit absoluto, segundo o PLHIS, era de 13.598 , e fora produzido $87,65 \%$ destas.

Considerando-se o déficit qualitativo, onde se situa a população prioritária do PMCMV (BRASIL, 2009) o problema habitacional poderia ter sido completamente resolvido. Mas, além de tal fator não ter acontecido, tal produção sequer diminuiu o número das áreas de ocupação irregular, que, conforme apontado, continua a crescer.

É fato inegável que se produziram habitações em número suficiente para que se solucionassem os problemas de moradia, mas os estudos atuais têm demonstrado que estes problemas têm sido agravados, pois o PMCMV impõe um processo de periferização através da construção em áreas distantes do centro da cidade, onde as terras são menos valorizadas, produzindo guetos por conta do modelo de construção verticalizado em condomínios fechados, processo ado- 
tado para o desenvolvimento majoritário dos empreendimentos, sobretudo no que diz respeito à Faixa 1. (PINTO, 2016).

Perpetuando, assim, um formato de segregação que vende a ilusão da segurança e tranquilidade pelo isolamento, ocultando conflitos e alimentando a autossegregação, cristalizando na exclusão a ilusão da garantia do direito à moradia.

Tal modelo sustentado pelo mercado de construção da cidade condiciona a reprodução das desigualdades, consolida uma geografia social do poder, desenvolvida para tornar moradores de "[...] comunidades de desespero econômico/zonas de sacrifício" (ACSELRAD, 2007, p. 7) em agentes de menor capacidade para influenciar o Estado.

[...] a produção habitacional proporcionada pelo Programa recebe muito maior influência da viabilidade econômica dos empreendimentos, do que da lógica de priorizações a partir da demanda habitacional existente no local ou da dinâmica urbana deste [...] as últimas transformações na política habitacional brasileira, oficializadas com a execução do PMCMV, ocasionaram uma transformação no mercado imobiliário que acarretou na inclusão de famílias com renda inferior a 10 salários mínimos no mercado da habitação como consumidores, prioritariamente. (PINTO, 2016, p. 77).

As informações apresentadas traçam o quadro do que tem sido a lógica de execução do PMCMV ao redor do país, e que se repete no município, diante dos levantamentos feitos, onde se relegou a produção habitacional a empresas privadas sem a devida fiscalização. Estas decidiram para quem e onde produzir as habitações e, diante da possibilidade de aumento da lucratividade, focalizaram suas produções nas faixas através das quais poderiam alcançar maior rentabilidade.

Assim, para os $19,11 \%$ de déficit - percentual relativo ao quantitativo - apresentado pelo levantamento do PLHIS, foram produzidas mais de 76,49\% das habitações, ou seja, para o déficit quantitativo de 2.598 habitações foram produzidas 8.837.

Dividida por faixa de renda, a produção do PMCMV foi de 2.856 habitações para Faixa 3 - 23,96\% das moradias produzidas, e de 6.251 moradias para Faixa $2-52,45 \%$ das moradias produzidas.

Esses números, além de revelar uma total inversão de prioridade no ato de planificação da política pública, esclarecem o porquê de não se ter avançado em direção à solução dos problemas habi- 
tacionais no município, uma vez que apenas $23,59 \%$ das moradias produzidas foram para a Faixa 1 - 2.812 moradias. Estabelecendo, ainda, um agravante, pois essas moradias foram produzidas nas bordas periféricas do município, em localidades sem inserção urbana, desrespeitando o decreto n. ${ }^{\circ}$ 7.499/2011 (BRASIL, 2011), que regula a implantação de empreendimentos do Programa Nacional de Habitação Urbana (PNHU) - parte integrante do PMCMV.

Os empreendimentos foram desenvolvidos em áreas externas da malha urbana, sem adequação de projeto ao ambiente de inserção, sem a presença de infraestrutura básica em sua maioria e sem que se assegurasse o cumprimento do compromisso de construção de equipamentos e serviços de atendimento à educação, saúde, lazer e transporte públicos às famílias inseridas (PINTO, 2016) perpetuando procedimentos de exclusão das comunidades empobrecidas. E ainda intensificando os processos de ocupação por parte das comunidades às quais não restam alternativas; populações historicamente excluídas, por conta da invisibilidade de seus problemas por parte do poder público.

O processo de crescimento da cidade observado no desenvolvimento dos 60 (sessenta) empreendimentos que se deram no recente período, evidencia o alinhamento do Estado a um modelo de gestão voltado à governabilidade empresarial, que atende as demandas do mercado, não existindo desordem ou incapacidade administrativa diante dos processos de crise, e sim, uma bem articulada trama de agenciamentos voltada para a manutenção estrutural da acumulação e exclusão, que tem se desenvolvido através das estratégias de planejamento do espaço urbano.

Esse modelo tem tornado a cidade mais atrativa e funcional para o capital, legitimando os responsáveis por estes processos e difundindo políticas urbanas voltadas para a competição globalizada no mercado das cidades.

Conclui-se que oito anos após a implementação do PMCMV em nível nacional, o déficit habitacional no país não diminuiu, o que coloca o município de Pelotas dentro do mesmo macroprocesso, segundo dados da Fundação João Pinheiro (2012) e Máximo (2017), permanecendo este entre 5,5 e 6 milhões de moradias. Fato este que se relaciona com a ação estatal que delegou à iniciativa privada o gerenciamento da política e esta impôs o modelo de pensamento único (VAINER, 2013) para a administração do Estado, segundo o qual 
a sobrevida da cidade consiste na transformação de seus espaços e equipamentos em mercadorias a ser comercializadas.

Assim, o PMCMV representou em todo o país - não sendo diferente em Pelotas, um novo discurso enraizado em velhos modelos de exclusão de muitos, para acumulação de poucos.

\section{CONCLUSÃO}

Os desafios de implantação de uma política urbana no Brasil, com o compromisso de resolver o problema da habitação, ainda estão longe de ser realidade para milhares de famílias que vivem em situação de posse, em condições irregulares ou submetidas a subsídios que as tornam prisioneiras de financiamentos a longo prazo e de alto custo para sua quitação.

Assim, como afirma Jacques Alfonsin (2006), não é o direito de propriedade que garante a função social da terra, mas o imóvel e o seu uso. Portanto, este estudo objetivou problematizar que a terra e a moradia não exercem no território nacional a função de proteger as famílias de trabalhadores, ao contrário, a terra e a moradia são ativos financeiros controlados pelo Estado e pelas grandes construtoras que compõem um complexo imobiliário globalizado cuja função é de criar o desejo de propriedade para que possam, com isso, capturar recursos públicos.

Com essa dinâmica, fortalecem-se processos intensos de desigualdade socioambiental, os quais revelam as formas sociopolíticas que configuram o sistema capitalista, legitimando a força dos proprietários imobiliários para que possam consumir o produto. As concentrações de recursos públicos para a construção de condomínios habitacionais não garantem o direito da moradia digna, bem como negam a situação de pobreza e de ocupação de território em que vivem muitas famílias. Nesse caso, o recorte sobre a realidade do município de Pelotas no Estado do Rio Grande do Sul revela tal afirmação.

Para que tenhamos garantido um índice de desenvolvimento humano expressivo, seria necessário que as políticas sociais públicas estivessem correlacionadas à perspectiva de uma reforma urbana e agrária, aliadas aos direitos sociais resguardados na Constituição Brasileira de 1988, forçando a diminuição dos índices de desigualdade e de pobreza, necessários para que a cidade se torne a cidade 
de quem nela vive, trabalha, constrói, consome, ou simplesmente, de quem existe e tem o direito de se manifestar.

\section{REFERÊNCIAS}

ABRAMO, P. A cidade caleidoscópica: coordenação espacial e convenção urbana. Rio de Janeiro: Bertrand Brasil, 2007.

ACSELRAD, H. Vigiar e unir: a agenda da sustentabilidade urbana? Revista VeraCidade, Salvador, ano 2, n. 2, p. 1-11, jul. 2007.

ALFONSIN, J. T. A Função Social da Posse como pressuposto de licitude ético-jurídica do acesso e da conservação do direito à terra. Revista de Direito Agrário, Brasília, DF, ano 19, n. 18, p. 173195, 2006. Disponível em: $<$ http://www.abda.com.br/revista18/pdf/ artigos/A\%20função.pdfß . Acesso em: 17 jul 2017.

ALVES, J. Regularização Fundiária: a cidade que temos e queremos. Pelotas, jul. 2017. 337 slides. Apresentação em Power Point. Relatório sobre ocupações irregulares no município de Pelotas.

. Regularização Fundiária: ocupações irregulares no município de Pelotas 2013. Pelotas, 16 de out, 2013. Apresentação feita ao legislativo municipal na Câmara de Vereadores. Apresentação em Power Point.

BRASIL. Decreto n. ${ }^{\circ}$ 7.499, de 16 de julho de 2011. Regulamenta dispositivos da Lei no 11.977, de sete de julho de 2009, que dispõe sobre o Programa Minha Casa, Minha Vida, e dá outras providências. Diário Oficial da União, Brasília, DF, 2011. Disponível em: <http:// www.planalto.gov.br/ccivil_03/_Ato2011-2014/2011/Decreto/D7499. $\mathrm{htm}>$. Acesso em: $17 \mathrm{fev} .2015$.

. Lei Federal n. ${ }^{\circ} 11.977$, de 7 de julho de 2009. Dispõe sobre o Programa Minha Casa, Minha Vida. Diário Oficial da União, Brasília, DF, 2009. Disponível em: <http://www.planalto.gov.br/ccivil_03/_ ato2007-2010/2009/lei/111977.htm> Acesso em: 8 jun. 2015.

. Lei $\mathrm{n}^{\circ} 11.977$, de 7 de julho de 2009. Dispõe sobre o Programa Minha Casa, Minha Vida - PMCMV e a regularização fundiária de assentamentos localizados em áreas urbanas; altera o Decreto-Lei no 3.365, de 21 de junho de 1941, as Leis nos 4.380, de 21 de agosto de 1964, 6.015, de 31 de dezembro de 1973, 8.036, de 11 de maio de 1990, e 10.257, de 10 de julho de 2001, e a Medida Provisória no 2.197-43, de 24 de agosto de 2001; e dá outras providências. Diário Oficial da União, Brasília, DF, 2009. Disponível 
em: <http://www.planalto.gov.br/ccivil_03/_ato2007-2010/2009/lei/ 111977.htm> Acesso em: 9 out. 2017.

ENGELS, F. A Origem da Família, da Propriedade Privada e do Estado. 11. ed. São Paulo: Brasiliense, 1987.

FUNDAÇÃO JOÃO PINHEIRO. Déficit habitacional no Brasil 2009. Belo Horizonte, 2012. Disponível em: $<$ http://www.fjp. mg.gov.br/index.php/docman/cei/deficit-habitacional/185-deficithabitacional-2009/file>. Acesso em: 12 jul. 2017.

LEFEBVRE, H. A Revolução Urbana. Belo Horizonte: Ed. UFMG, 1999.

. O Direito à Cidade. 5 ed. São Paulo: Centauro, 2016.

MARICATO, E. Brasil, cidades alternativas para a crise urbana. Petrópolis, RJ: Vozes, 2013.

MAXIMO, L. Déficit habitacional aumenta com a recessão. Valor Econômico, São Paulo, março 2017. Disponível em:<http://www.fjp. mg.gov.br/index.php/fjp-na-midia/3785-1-3-2017-deficit-habitacionalaumenta-com-a-recessao >. Acesso em: 12 jul. 2017.

PELOTAS. PLHIS Pelotas: Plano Local de Habitação de Interesse Social de Pelotas. Pelotas, 2013. Disponível em: <plhispelotas. blogspot.com>. Acesso em: 22 maio 2014.

PINTO, J. V. Contribuições para estudo do "Programa Minha Casa, Minha Vida" para uma cidade de porte médio, Pelotas/RS. 2016. Dissertação (Mestrado) - Programa de Pós Graduação em Arquitetura e Urbanismo, Universidade Federal de Pelotas, 2016.

ROLNIK, R. Guerra dos lugares: a colonização da terra e da moradia na era das finanças. São Paulo: Boitempo, 2015.

. O que é Cidade. 4 ed. São Paulo: Brasiliense, 2012.

SANTOS, M. A Urbanização Brasileira. São Paulo: Editora da Universidade de São Paulo, 2009.

VAINER, C. A cidade do pensamento único: desmanchando consensos. Petrópolis, RJ: Vozes, 2013. 